\title{
APPLICATION OF A METHODOLOG Y FOR STRUCTURING AND EVALUATING A BUSINESS OPPORTUNITY FOR THE COLOMBIAN PETROLEUM COMPANY - ECOPETROL S.A.
}

\author{
Mario Castillo* \\ Department of Industrial Engineering \\ Universidad de los Andes \\ Bogotá, Colombia \\ E-mail:mcastill@uniandes.edu.co \\ William Segura \\ ECOPETROL S.A. \\ Bogotá, Colombia \\ E-mail:william.segura@ecopetrol.com.co \\ Carlos-Julio Salcedo \\ ECOPETROL S.A. \\ Bogotá, Colombia \\ E-mail: Carlos.Salcedo@ecopetrol.com.co \\ Luis-Jose Novoa \\ Department of Industrial Engineering \\ Universidad de los Andes \\ Bogotá, Colombia \\ E-mail: lu-novoa@uniandes.edu.co \\ Diana Lesmes \\ Department of Industrial Engineering \\ Universidad de los Andes \\ Bogotá, Colombia \\ E-mail: d-lesmes@uniandes.edu.co
}

\begin{abstract}
In this work we designed and applied a decision analysis methodology for the analysis and evaluation of a Business Opportunity (BO) in oil industry, oriented to recommend the best alternative for electricity supply and distribution for a specific area of oil exploitation. An economic model, a probabilistic model and an Analytic Hierarchy Process model interact to achieve the objective. For this specific high investment (around USM\$ 600) BO, the work produced a recommendation on whether to carry the $\mathrm{BO}$ or not, and suggested an alternative to implement.
\end{abstract}

Keywords: analytic hierarchy process, energy generation, business opportunity in oil industry

${ }^{*}$ Corresponding author 


\section{Introduction}

Ecopetrol, the Colombian Petroleum Company, currently produces 630,000 barrels of equivalent oil per day. The company objective is to produce 1 million of BOPD by 2015. Among its strategic objectives are the development of fields in the operations areas, the increase of the productivity in those areas (increase the recovery factor (RF)), and increase the internal and external commerciality, among others. Because of this, the creation of Business Opportunities (BOs) to reach their strategic objectives is of the greatest importance for Ecopetrol, taking into account the big challenges in which the company is committed.

Ecopetrol considered important to have people trained in decision analysis under risk and uncertainty, and with the support of Los Andes University made workshops for the application of methodologies aiming to formalize the structuring and preliminary evaluation process of BOs of the Company's Management of Business Opportunities Model (MBOM). This methodological support is aligned with the objective of the Company's Opportunities Group that aims to "propitiate the development of BOs that are able to extract the biggest value of the assets of exploration and production, through the development of business cases that lead to propound projects to include in the investment portfolio of the company. To make this possible, it should be guaranteed that those projects are properly defined and structured".

This article begins with the description of the objectives of the project; followed by the presentation of the general methodology developed for the evaluation of BOs; afterwards, this methodology is applied to an opportunity, aimed to recommend the best alternative for the energy supply and distribution in a specific area of oil exploitation of Ecopetrol, and concludes with a summary of the main results and conclusions.

\section{Objectives}

The project conceived jointly between Los Andes University and Ecopetrol's Opportunities Group was aimed to fulfill the following general objectives:

1. Carry out training for a group of Ecopetrol's professionals in the topics of Decision Analys is under Uncertainty and Risk Analysis.

2. Provide technical support in the realization of Decision Analysis under Risk and Uncertainty workshops to Ecopetrol's Opportunities Group engineers in the context of BOs evaluation.

3. Perform a pilot project to design a preliminary methodology for the structuring and preliminary evaluation of BOs, and apply it to a specific BO.

4. Develop a general methodology oriented to the structuring and evaluation of BOs that may be used by Ecopetrol as part of its MBOM.

5. Produce a set of conclusions and recommendations to the Ecopetrol's Business Opportunities Group regarding the process made with the support of the University.

\section{Methodology}

The methodology developed for the evaluation of $\mathrm{BO}$ is composed by seven stages, whose sequence is summarized in Figure 1 (see Appendix). The purpose of the Methodology is to determine if a BO exists and produce recommendations regarding which are the best alternatives to perform the $\mathrm{BO}$. 


\section{Methodology application}

The Methodology was applied to an Ecopetrol's specific BO. The results of the application in the main stages of the methodology are described below.

\subsection{Description of the business opportunity}

The opportunity has the objective of assuring the supply of electric energy and the reliability of the distribution system, for the development of the production fields of the Gerencia de la Regional Magdalena (GRM), and in this way to contribute to Ecopetrol's production objective.

\subsection{Main as pects of the Problem}

The main aspects of the problem that were taken into account are: technical, economical, regulatory, commercial, environmental, property management, synergies, health security and environment (HSE), and social.

\subsection{Decision alternatives}

The decision alternatives were built from the combination of some decision variables. A total of eight alternatives were evaluated. The alternatives were grouped according to the type of fuel used for the energy generation: the A represents gas, the $\mathrm{B}$ coke and the $\mathrm{C}$ the national energy transmission system.

\subsection{Economic model}

An economic model was built with Montecarlo simulations using Crystal Ball. According to the economic model the alternatives ranking, with respect to the mean of the present value (PV) of the cost, ordered from the cheapest to the most expensive was: B2, B1, A5, A3, A1, A4, A6 and C1. The Montecarlo simulation in Crystal Ball included as random variables of the economical model the following variables: investments, the national energy transmission system fee, the coke price, the gas price and the energy demand. The parameters of the probability distribution were assigned based on the estimations de livered by the project's work team. The distribution of the PV of the cost of each alternative is presented in Figure 2.

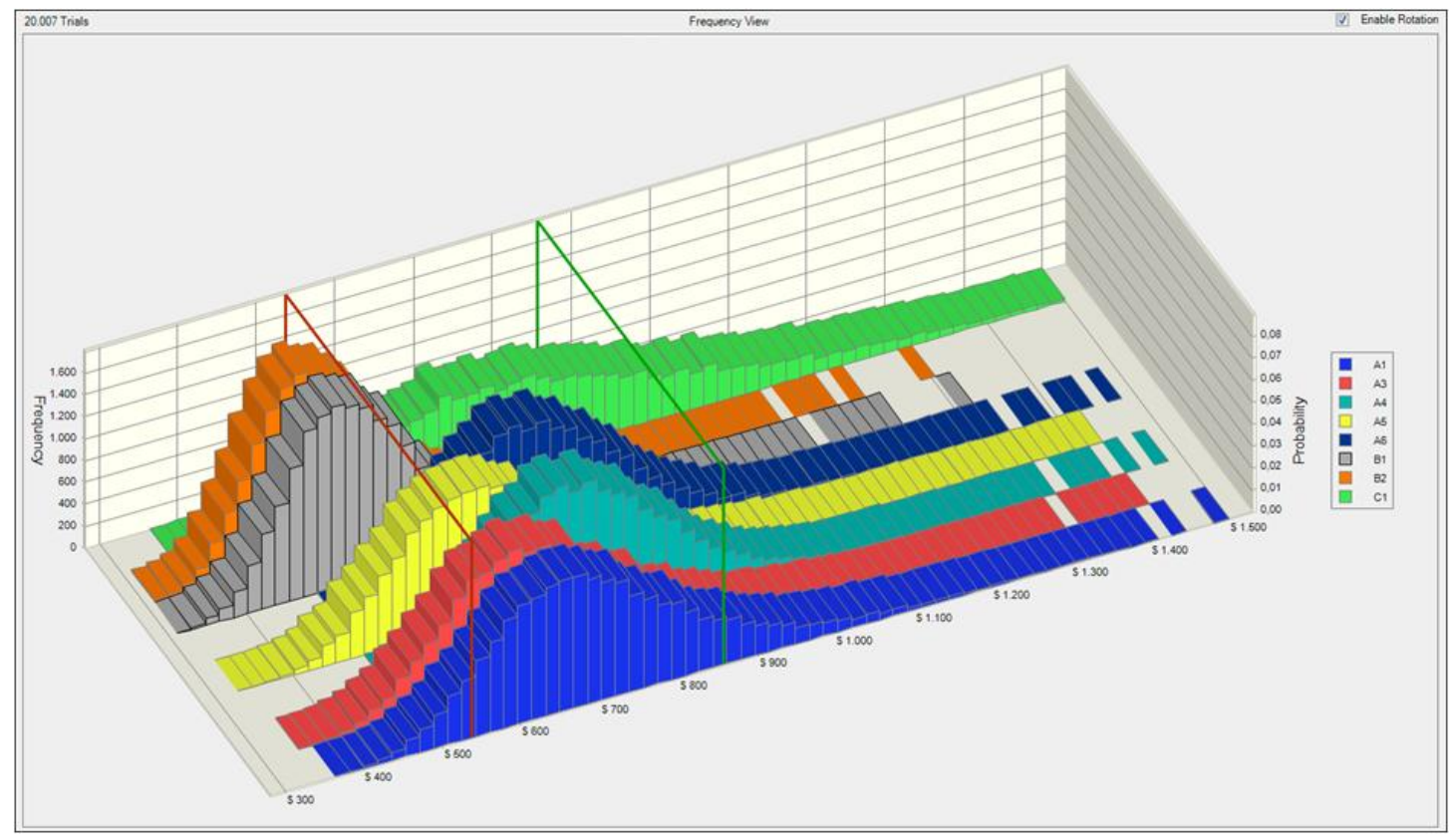

Figure 2. Methodology for the Evaluation of BOs. 


\subsection{Qualitative model}

The AHP was used to integrate the results of the economic model and the qualitative criteria in the alternatives evaluation. Figure 3 (see appendix) presents the final structure of the benefits and the risks hierarchies for the valuation of the eight alternatives under consideration.

The integration of the alternatives evaluation under the Benefits and Risks hierarchies was made using the negative additive formula proposed by Saaty (2005). Once the definitions of the criteria were validated, Ecopetrol's experts group evaluated the final eight alternatives using the AHP methodology in a six hours workshop organized by the University. Alternatives B1 and B2 had the best performance according to the Benefits hierarchy, while alternatives $\mathrm{A} 1$ and $\mathrm{C} 1$ had the best performance according to the Risks hierarchy.

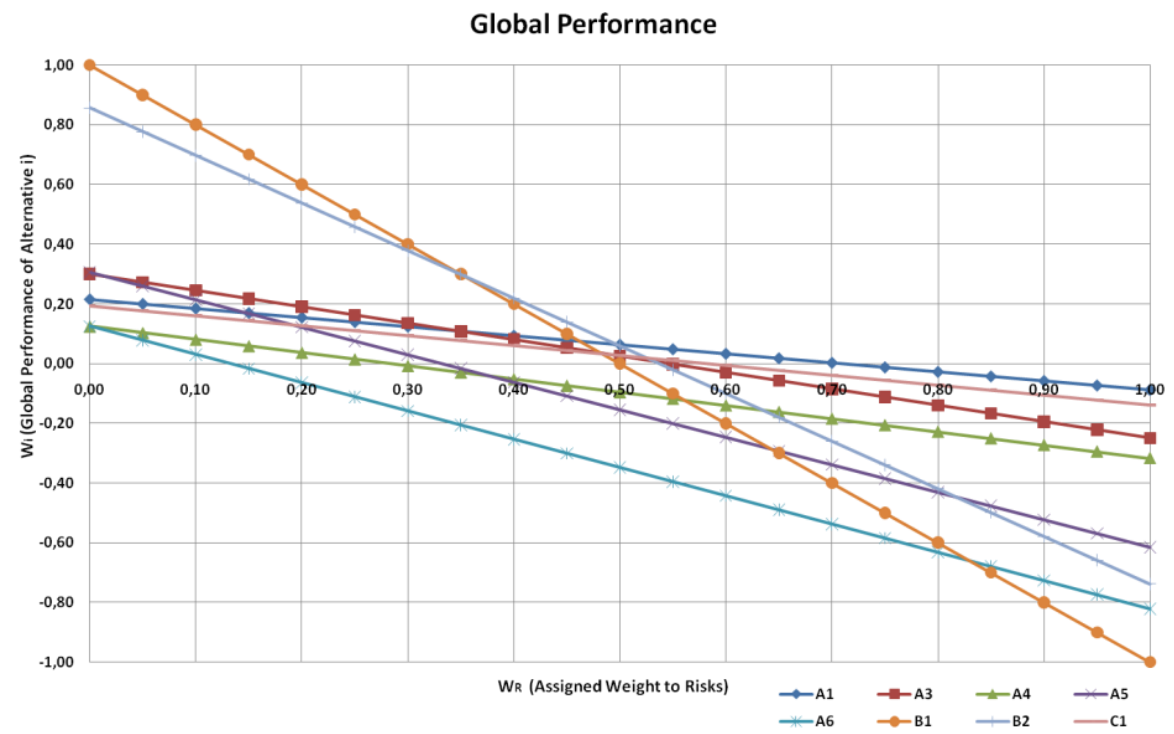

Figure 4. Sensitivity Analysis of the Alternatives' Global Performance

Figure 4 shows that if the Risks weight is under 0.45 the alternatives B1 and B2 (based in coke) dominate the other alternatives in terms of global performance. But if the Risks weight is over 0.45 the alternatives $\mathrm{A} 1$ and $\mathrm{A} 3$ (based in gas) dominates the other alternatives. The managers in charge of this $\mathrm{BO}$ selected the alternatives having under consideration the nature of the project and taking into account the Ecopetrol's corporate strategy.

\subsection{Final Evaluation}

The final evaluation of this opportunity, stage 6 of the Methodology, will be made measuring its performance in relation to thy strategic objectives identified by Ecopetrol's Opportunities Group. This stage is currently in implementation phase.

\section{Conclusions}

The conformation of an interdisciplinary group with an integral knowledge of each BO is of particular importance and should be considered as a critical factor for the proper implementation of the methodology. 
The results presented are the consequence of the rigorous application of the Methodology for the evaluation of BOs. This made possible that the discussions regarding the decision problem were made in an ordered and structured way, which allowed the Ecopetrol's work team to measure with precision the Risks and Benefits of each of the alternatives.

The alternatives based in coke had a higher global Risks level than the alternatives based in gas, but at the same time, the alternatives based in coke had a better performance in the global Benefits than the alternatives based in gas.

For the final decision regarding the alternative that had to be chosen, the company's managers took into account the risk level that the company was willing to accept in this project. If Ecopetrol used a Risks weight below 0.45; alternative B1 and B2 (based in coke) dominate the other alternatives according to the global performance.

It is particularly important for the team to identify and define in a precise way the strategic objectives that will be used to evaluate the different $\mathrm{BO}$, according to their nature. The team had identified three types of BOs to be analyzed and evaluated: opportunities for fields' development, for new technologies implementation and for infrastructure building.

And last but not least, it is important to highlight that Ecopetrol is going to implement this Methodology as a standard structured protocol for the evaluation of high economic impact BOs. In the case of this BO, the investment will be in the order of USM\$ 600.

\section{REFERENCES}

Castillo, M. (2010). Toma de Decisiones en las Empresas: Entre el Arte y la Técnica. Bogotá: Ediciones Uniandes.

Christensen, P. M., \& Peterson, R. (1989). Opportunity identification: The contribution of entrepreneurship to strategic management. Denmark: Aarhus University Institute of Management.

Dey, P. K. (2006). Integrated project evaluation and selection using multiple-attribute decisionmaking technique. International Journal of production economics (103) , 90-103.

Gorini de Oliveira, R., \& de Moraes Marreco, J. (2006). Natural gas power generation in Brazil: New window of opportunity. Energy Policy, 2361-2372.

Maradei. \& Castillo, M. (2010). Metodología para la identificación y estimación del impacto de los factores críticos de éxito de los proyectos de la gerencia de desarrollo de transporte de ecopetrol S.A. Bogotá, Colombia: Universidad de Los Andes.

Salinas, J. (2009). Análisis de decisiones estratégicas: en entornos inciertos, cambiantes y complejos. Buenos Aires: Cengage learning.

Saaty, T. \& Vargas, L. (1994). Decisions Making in Economic, Political, Social and Technological Environments with the Analytic Hierarchy Process, University of Pittsburgh. 
Saaty, T. (2005). Theory and applications of the Analytic Network Process: decision making with benefits, opportunities, costs and risks, University of Pittsburgh.

Wang, J. -J., Jing, Y. -Y., Zhang, C. -F., \& Zhao, J. -H. (2009). Review on multi-criteria decision analysis aid in sustainable energy decision-making. Renewable and Sustainable Energy Reviews 13, 2263-2278.

Weijermars, R. (2009). Accelerating the three dimensions of E\&P clockspeed : A novel strategy for optimizing utility in the Oil \& Gas industry. Applied Energy. 


\section{Appendix:}

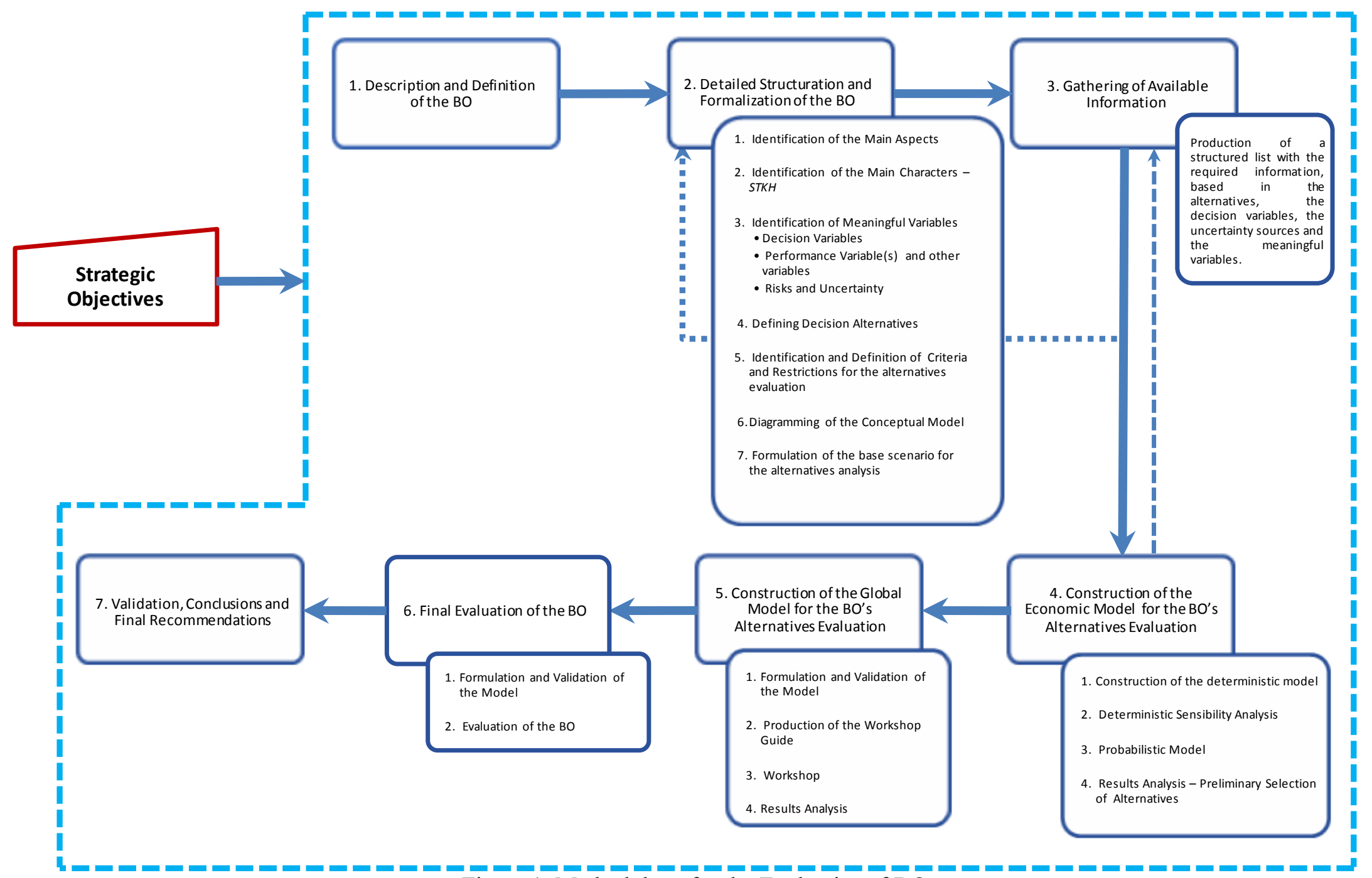

Figure 1. Methodology for the Evaluation of BOs. 


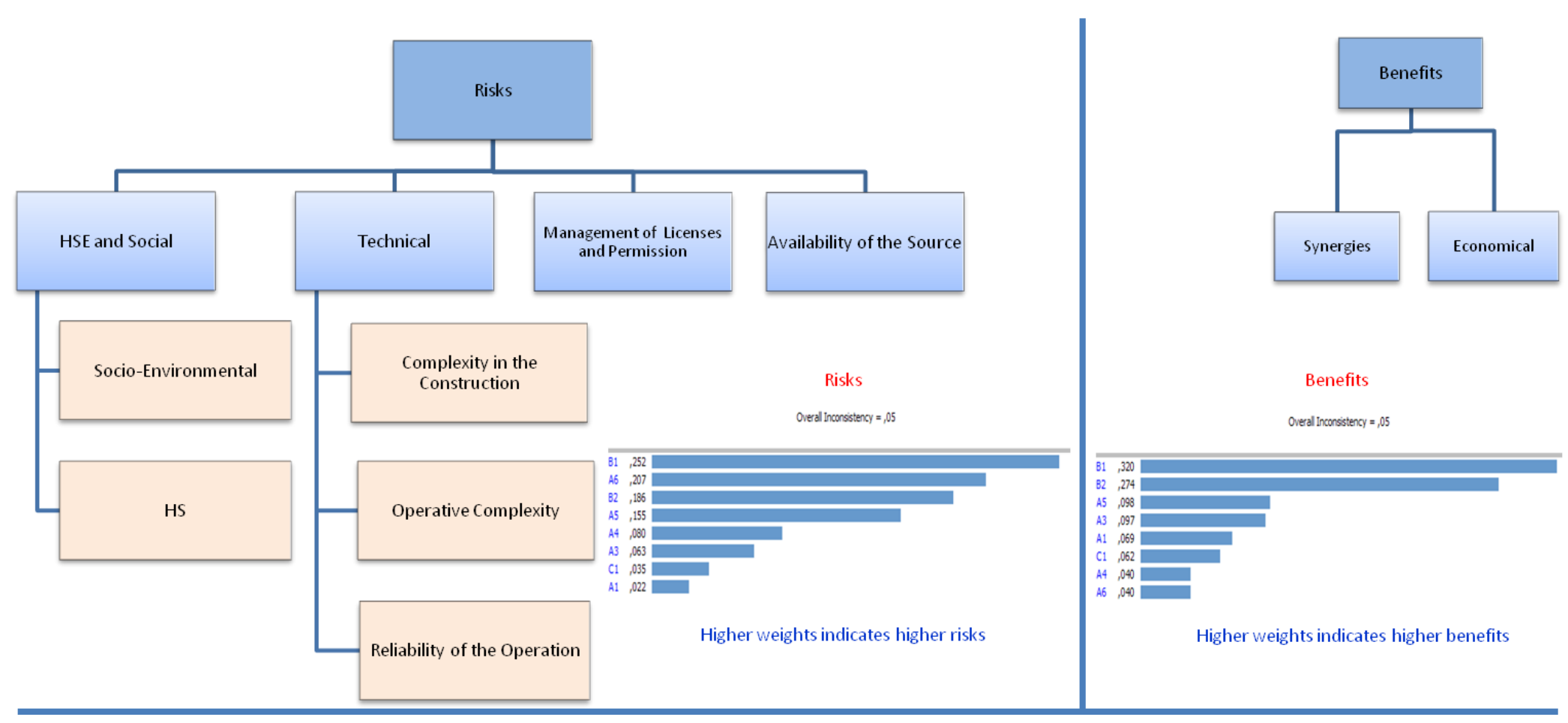

Figure 3. Benefits and Risks Hierarchies Results 